\title{
Reactive and Robust Planning of Moroccan Citrus Chain Based on Multi-agent System and Performance Indicators
}

Hind Moutaoakil and Hicham Jamouli

Laboratory of Industrial and Computer Engineering (G2I), National School of Applied Science, Ibn Zohr University, Agadir 80.000, Morocco

\begin{abstract}
As part of improving services done for various clients in all Moroccan areas, Moroccan exportation group of fruits and vegetables in collaboration with their packaging units and producers, tends to cooperate in order to face with international competitiveness. Indeed, the complexity of networks of partners has led policy-makers to implement new techniques and tools to help control different processes. For this reason, the implementation of a permanent monitoring of different operations ranging from production, packaging, and distribution of perishable products has become paramount. This article aims to propose a model of multi-agent citrus supply chain, based on indicators for monitoring and evaluation of performance of its logistics systems, in order to build a new independent, robust and responsive chain, and to optimize and control the flow of materials and information between the different actors and stakeholders of the chain.
\end{abstract}

Key words: Citrus, supply chain, supply chain operation reference, multi-agent system, export, performance indicator.

\section{Introduction}

In the current firms, communication, coordination and collaboration between different actors in a supply chain become a key economic issue and a serious competitive advantage. The supply chain is a complex macro-system composed of many factors: the truth intervening organizational structures and relationships between them, the decentralization of policy decisions and the offshoring of tasks related to production $[1,2]$.

The management of a supply chain can be based on the management of its processes and its performance depends on the relevance of strategic decisions, tactical or operational responses at each process. This performance is measured using indicators interconnected and reflecting the impact of different actions along the supply chain.

Our article occurs in four sections: first, a literature

Corresponding author: Hind Moutaoakil, Ph.D. candidate, industrial engineer, research field: logistics. E-mail: hind.moutaoakil@gmail.com. review summarizing existing models of modeling supply chains; second, a presentation of the principle of distributed modeling based on multi-agent approach and its impact on our case studied system; third, we project the model selected on Moroccan citrus supply chain; finally, we proposed a model of decision that is based on mixed architecture for reactive and robust chain compared to disturbances and uncertainties.

\section{State of the Art}

\subsection{Supply Chain Modeling}

Performance and its measure are currently the focus of studies, practitioners and academicians. In logistics, companies start caring of the implementation, measurement and performance improvement of their supply chain. Based on some contributions, particularly important, many models of reference are made for design, implementation, the measurement and performance improvement of the supply chain. As part of our study, we will describe these contributions 
and put into perspective their participation as part of our problem. These are models of Porter, Gilmour, Cooper, SCOR (supply chain operations reference) frameworks, ASLOG (French Logistics Association), and EVALOG (a global benchmark standard for evaluating logistics for the automotive industry) [3-8].

\subsubsection{Porter}

Porter developed, in 1986 in the book "The Competitive Advantage of Nations" [3], some generic strategy concepts that became nowadays standards in strategy domain.

Complementing previous contributions, Porter also published "Strategic and Competitive Choices" in which he describes the concept of "competitive advantage". Porter's work offers a description of the value chain. This analysis tool proposed by Porter is a relevant approach to supply chain focusing on the added value of different activities.

\subsubsection{Gilmour}

Gilmour [4] proposed a framework of strategic audit for improving the performance of the supply chain. For this reason, he applied 11 skills to build a grid with defined characterization in five dimensions characterizing the mastery of the chain logistics.

\subsubsection{Cooper}

Cooper [5] proposed a repository that guides the steering and redesign of the extended supply chains, and it is based on three elements: the processes describing the activities that create value for the customer, the steering components of these processes and the structure of the physical network of different companies constituting the chain.

\subsubsection{SCOR}

SCOR [6] is a reference model initialized in 1996 by Supply Chain Council aimed to define a guide for standard companies, which is presented by Stephens, and includes a description of typical process, a pattern of connections between them, standard performance indicators and identifying best practices associated.

The model replaces the internal supply chain of the company within the extended supply chain with customers and suppliers. It identifies five levels of process: planning, supplying, manufacturing, return, and an additional process which is introduced by the SCOR model: process "enable". It represents the supports activities of the supply chain management.

\subsubsection{ASLOG}

ASLOG [7] has built a repository based on one developed by Volvo in the 1990s.

This repository has been "improved" and it forms an interesting baseline for judging the relevance of a logistics system. The Toolkit Logistics ASLOG aims to help businesses improve their logistics performance.

\subsubsection{EVALOG}

EVALOG [8] is a global benchmark standard for evaluating logistics for the automotive industry. It is the result of collaboration between GALIA (Group for the Improvement of Links in the Automotive Industry) Odette International Limited and the AIAG (Automotive Industry Action Group).

Based on the OLE (Odette Logistics Evaluation) repository and MMOG (Materials Management Operations Guidelines), respectively used in Europe and the United States, EVALOG allows self-assessment or audit logistics partner sites (plants, suppliers) in the form of a quiz and calculating a score.

\subsection{Comparison of Existing Logistic Models}

We described the models of Porter, SCOR, Gilmour, Cooper, EVALOG and ASLOG.

In order to assess their contribution as part of the diagnostic methodology of the supply chain, Valla [9] proposed to compare their visions by producing a summary table.

The points of comparison must correspond to some criteria of relevance against a problem of diagnosis. These points are:

- number and nature of the identified processes. Three types of processes are identified: "operational" processes that represent the flow of products along the 


\section{Reactive and Robust Planning of Moroccan Citrus Chain Based on Multi-agent System and Performance Indicators}

chain, relating to steering (making and information flow) and supporting processes describing the support activities of the company. The criterion "nature of the identified process" allows homogeneity of the items proposed in different models;

- level of detail of the processes described;

- analysis methodology which identifies the proposed method of analysis associated with the model;

- support tools which are supporting tools that can be used to detect malfunctions and to analyze performance;

- best practices identified by the models.

Table 1 summarizes the points of intersection between the models mentioned before.

The benchmarks studied show the difference in typology between the various processes constituting supply chain: physical process or informational/decision. Different views also show the importance of comprehensive and cross-account flows. The detailed comparison of the models in the summary table presented (Table 1) allows us to draw some conclusions:

- The SCOR model is a reference much more accurate than other models reference;

- The description of operational process is well detailed, documented and the best practices are identified. The monitoring processes are very oriented to functions (planning, return) and put forward the little cross steering the supply chain. The notion of orientation or customer service is not emphasized in this model;

- Cooper [4] and Gilmour [5] models provide an interesting cross vision in steering the supply chain. The description of the proposed Cooper process and the characterization grid of Gilmour are, in particular, strong contributions;

- Identification of key business operations using the value chain of Porter [3] is an interesting contribution to the diagnosis of the supply chain. He focuses his attention on the value added by different activities.

In the present work, our study is based on the SCOR model that has major objectives to form a comprehensive view of the entire supply chain by facilitating the representation of physical, informational and financial flows from the first supplier to the ultimate client.

Table 1 Synthesis and comparison of different models.

\begin{tabular}{|c|c|c|c|c|c|c|}
\hline Criteria & Porter & SCOR & Gilmour & Cooper & EVALOG & ASLOG \\
\hline Framework & General & General & General & General & $\begin{array}{l}\text { Automobile } \\
\text { industry }\end{array}$ & General \\
\hline $\begin{array}{l}\text { Relating to the } \\
\text { physical flow }\end{array}$ & 5 & 3 & 3 & 0 & 3 & 5 \\
\hline Number of Relating to pilotage & 0 & 2 & 3 & 8 & 2 & 3 \\
\hline $\begin{array}{ll}\text { processes } & \begin{array}{l}\text { Relating on support } \\
\text { activities }\end{array} \\
\end{array}$ & 4 & 1 & 5 & 0 & 1 & 2 \\
\hline Total & 9 & 6 & 11 & 8 & 6 & 10 \\
\hline Level of detail of process & Process & $\begin{array}{l}\text { Detailed description } \\
\text { of activities }\end{array}$ & Process & Process & $\begin{array}{l}\text { Detailed } \\
\text { description of } \\
\text { activities }\end{array}$ & $\begin{array}{l}\text { Detailed } \\
\text { description of } \\
\text { activities }\end{array}$ \\
\hline Support tools & $\begin{array}{l}\text { Value } \\
\text { chain }\end{array}$ & $\begin{array}{l}\text { Evaluation grids; } \\
\text { Performance } \\
\text { Indicators }\end{array}$ & $\begin{array}{l}\text { Characterization } \\
\text { grid }\end{array}$ & $\begin{array}{l}\text { Steps of } \\
\text { description of } \\
\text { the network and } \\
\text { identification of } \\
\text { cast }\end{array}$ & $\begin{array}{l}\text { Questionnaire } \\
\text { of good } \\
\text { practices by } \\
\text { activity }\end{array}$ & $\begin{array}{l}\text { Questionnaire } \\
\text { of good } \\
\text { practices by } \\
\text { activity }\end{array}$ \\
\hline $\begin{array}{l}\text { Best practices identified by } \\
\text { models }\end{array}$ & - & $\begin{array}{l}\text { Best practices by } \\
\text { element of process; } \\
\text { Performance indicators } \\
\text { by element of process }\end{array}$ & $\begin{array}{l}\text { Benchmark } \\
\text { profiles based } \\
\text { on grid } \\
\text { characterization }\end{array}$ & $\begin{array}{l}\text { Identified } \\
\text { composants of } \\
\text { pilotage }\end{array}$ & - & - \\
\hline
\end{tabular}




\subsection{Methodology}

This paper proposes a method for measuring the performance of a supply chain based on the process approach and multi-agent. At first, this method provides a clear and precise modeling of this chain, which consists of the cutting process and then agent formalism. Then, it calls for identification of performance indicators approach guided by this division. This approach allows declining the strategic vision of the draft measure performance on all levels of the chain to identify indicators to monitor the extent of involvement of each level to achieve this vision. This approach allows declining the strategic vision of the draft measure of performance on all levels of the chain to identify indicators of monitoring the extent of involvement of each level to achieve this vision. The method is illustrated through examples from a food case of measuring the performance of the Moroccan citrus supply chain.

In our study, we will begin by modeling the citrus chain based on the SCOR model to understand the operation of each of its participants, to facilitate decision and improve its performance.

Then we will design a system consisting of a set of agents located in a certain environment and interacting according to certain relations. To this end, we propose to use multi-agent approach.

Finally, we will expose some elements of performance measurement of supply chains to refine our choice of performance indicators needed to evaluate our approach and position relative to others.

2.3.1 SCOR Model, Definition and Structure Contribution

\subsubsection{Definitions}

SCOR is a modeling tool. It defines an approach, processes, indicators and best practices to represent, assess and diagnose the supply chain. This methodology based on the customer is generic, rigorous, comprehensive and structuring. It provides participants of the chain by a common and standardized language (alphabet, process and indicators) responding to a single definition needed to accelerate the internal and external integration of firms.

\subsubsection{General Structure of the Model}

The SCOR model is constructed in a hierarchical form. The first three levels of this hierarchy are standard: main level, configuration level, level activities. Decomposition levels beyond the third level correspond to the description of the individual company practices of their strategy, the specifics of their business or organization sector which is not an appropriate generic objective of the model [10].

\subsubsection{Contribution of the SCOR Model}

The contribution of the mode is as follows:

- Securing the supply chain. Representation made through the model allows the detection of unique potential sources of supply, organizational failures, redundant treatments, and information flows via tortuous routes, etc.. The SCOR model thus leads to identifying the critical paths of the supply chain (nodes and links). This is essential because it is necessary to focus its resources on critical points;

- Aligning the supply chain. First, thanks to the model, the supply chain can meet the strategic goals. Moreover, the SCOR model enables rapid configuration and reconfiguration of the supply chain, making possible the development of economic models to meet the changing environment. The SCOR model thus provides supply chain capacity to be robust thanks to the structure of the model, but also resilient thanks to possible reconfigurations rendered indispensable;

- Other contributions. Being generic, the model fits most problematic supply chain from strategic changes such as mergers/acquisitions of businesses, analyzes preceding the introduction of new information systems, etc.. Of course, like any cross project, conducting a project on the SCOR model requires the support of the management and the commitment of all 
those involved in the project. Moreover, it is clear that the step of forming the model is essential to the success of the project key.

\subsubsection{Multi-agent Approach}

The multi-agent systems, issued from the work of distributed artificial intelligence, provide relevant tools for modeling and simulation of industrial problems [11]. The properties that define agents, namely autonomy, proactivity, responsiveness and sociability [12], make the approach of modeling multi-agent particularly suited to the problem of modeling and simulation of supply chains [13].

Indeed, a multi-agent system is a set of agents who have some autonomy, a degree of artificial intelligence and a representation of their environment. They interact with it, and they can take the initiative, communicate with each other and adapt to different situations [14, 15]. The need for these concepts in our collaborative platform justifies, to some extent, the choice of multi-agent approach.

\subsubsection{Performance Measurement}

\subsubsection{What Measures the Supply Chain?}

Several factors explain why leaders need specific measures to manage the supply chain, including [16]:

- the absence of measures that express the performance of the entire chain;

- the need to go beyond internal measures and cover the entire supply chain;

- the need to determine the interaction between the performance of each player and the chain as a whole;

- complexity of supply chain management;

- the necessity to align activities and share information about the performance to implement a strategy to achieve the objectives of the supply chain;

- the desire to widen the viewing angle within the supply chain;

- the desire to spread the positive and negative functional changes in the supply chain effects;

- the necessity to differentiate supply chain to gain competitive advantage;

- the desire to promote cooperation between the functions in companies and among members of the supply chain.

\subsubsection{Elements of Performance Measurement}

Performance measurement in the supply chain "is interested in improving the functioning of the media production process and increasing overall productivity" [17]. Generally, tools and approaches of performance measurement have been adapted to the context of performance evaluation in supply chains. One of these tools is the dashboard.

Indeed, Bouquin [18] defines the dashboard as "an instrument for measuring a set of indicators which allows decision makers to be aware of the status and evolution of the systems they are operating". The latter definition refers to the notion of indicator as a means of measuring performance.

Indeed, in the scientific literature, we identify several definitions of the concept of performance indicators:

- "A performance indicator is quantitative data that express the effectiveness and/or efficiency of all or part of a (real or simulated) system, compared to a standard, determined and accepted plan as part of a business strategy" $[19,20]$;

- "A performance indicator is a numerical translation of the strategic objectives of the organization" [21];

- "A performance indicator is an information which must help an individual actor or organization to drive the course of action towards achieving a goal, or to allow him to evaluate the results" [17];

- "A performance indicator is associated with a 'pilot action' which should be operational relevance" $[18,22]$.

The indicators can be grouped into two categories, as presented by Chan [23]:

(1) Quantitative: it is a measure of a physical quantity. In this type of measurement we find variables such as:

- costs: cost of distribution, production costs, storage costs, etc.;

- use of resources: machine capacity, energy use, etc.; 
(2) Qualitative: an assessment on a scale of subjective value [24] as:

- quality: customer satisfaction, customer response times (between order and delivery), etc.;

- flexibility: machine flexibility, routing flexibility, flexibility of labor.

Regarding the result of our work, it seems interesting to characterize the performance of our approach to disturbances (break of stock, the delay in time, overhead, etc.) and environmental fluctuations such as indicators that will be detailed later.

\section{Case Study}

Our study is conducted on the citrus industry, and we use the SCOR model to break our chain process in order to better visualize the different historic flows between the actors and bring out its flaws.

The citrus industry, being the first group of fruits exported in Morocco, is considered as a strategic sector involved of trade balance and is raised to the highest priorities of agricultural policy. Having highly profitable public investment and incentives for production as an export crop irrigated, this sector has been known since the 1960s sustained development.

The supply chain of this industry involves several actors from production to marketing of citrus. It is a multi-actor chain. The major actors of the chain of citrus industry are :

- farm: production;

- station: packaging;

- group : export;

- platform : distribution.

The packing citrus station is considered as firm pivot of our chain. For this, our upstream chain will consist of the farm producer as a major player, and the downstream channel will be composed of the exporting citrus group (in Morocco) and distribution platform (abroad).

\subsection{Modeling of the SCOR Citrus Industry}

\subsubsection{Citrus Supply Chain Process}

According to the International Standard ISO/DIS8402, a process is a set of resources (personnel, facilities, equipment, techniques and procedures) and related activities that transform inputs into outputs elements. The main processes of the Moroccan citrus export chain seem:

\subsubsection{Planning Process}

Programming in the citrus industry is loop, beginning by the producer, while returning it to him.

This process can be decomposed into two sub-processes:

- Sub-process long-term planning: it consists on the design of the overall export program throughout the campaign which we identify by the symbol " $N$ " specifying the tonnage, destinations, means of transport to use, etc.;

- Sub-process short-term planning (weekly): it consists on actual weekly schedule of the week symbolized by " $s+1$ " and throughout the campaign $N$.

\subsubsection{Supply Process}

To satisfy its client, the packing station which we identify by symbol " $S$ " involves several stakeholders in the preparation and packaging of its citrus. These stakeholders are packaging suppliers, raw material (citrus), packaging supplies (wax, etc.), transport partners and others. The main objective of supply process is to provide the chain studied by all the necessary supplies.

\subsubsection{Packaging Process}

The packaging process comes just after the completion of the supply process. We also note that the two processes are continuous in time. This process involves the pivot of the citrus supply chain and aims to describe the various steps of citrus packaging.

\subsubsection{Distribution Process}

It concerns the downstream chain represented by the exporter citrus group. Once packed, the packing station delivers its citrus to exporter group who handles marketing for different markets through its platform abroad.

3.1.2 Global Mapping of Process Citrus Supply Chain 
After presenting each process of the citrus chain, we propose a global mapping (Fig. 1) from supplier's supplier arriving at the pre-ultimate client.

\subsection{Multi-agent Modeling of Citrus Chain Processes}

After having decomposed our supply chain to processes, we will form a system consisting of a set of agents located in a certain environment and interacting according to certain relations. For this reason, we propose in our work to be inspired from the multi-agent approach.

Each process will be pre-modeled by a multi-agent system, then we will regroup all the systems in a global mapping.

\subsubsection{Agent 1: Supply Process}

According to the results obtained previously, the major pillars of completion of the supply process are: packaging (Agent 1'"') and transport (Agent 1') of citrus (Agent 1"). Based on the multi-agent system and our previous results, we represent the supply process in Fig. 2.

\subsubsection{Agent 2: Packaging Process}

This process uses four pillars: chemical products used in processing citrus fruit from the farm, citrus, packaging and water used in the packaging line.

A model of multi-agent system is proposed as represented in Fig. 3.

\subsubsection{Agent 3: Distribution Process}

The distribution process is performed at group level exporter. Once packed, the packing group delivers its citrus to exporter group (refrigerated trucks) which handles marketing for various markets including: direct customers, distribution platforms or brokers.

It is noticed that citrus are delivered to different clients with two types of shipping: conventional transport and container transport.

The model in Fig. 4 illustrates the major pillars of the distribution process.

\subsubsection{Agent 4: Planning Process}

Planning is the key stage of citrus logistic chain, and, following this planning, the sequence of the chain from the farm to the final customer begins.

For this, the successful programming step means successful on all chain and vice versa. This programming covers all operations done in the chain: supply of raw materials, packaging and dispatching to the customer.

The programming in the sector of citrus is loop, commencing with the producer while turning to him. For this purpose, it is considered that process as the permanent staff at all levels of the chain. Therefore, the modeling agent on the process is proposed as in Fig.5.

For this purpose, it is considered that process as the permanent staff at all levels of the chain. For this, the modeling agent on the process is proposed as in Fig. 5.

\section{Mapping the Global Chain of Citrus}

After modeling the multi-agent processes with key parameters for each, we combined between the proposed scheme and the decomposition of processes to bring out a new model of global mapping of citrus chain studied (Fig. 6).

Modeling the supply chain has helped to determine the various points on which we must focus to improve our citrus supply chain Moroccans.

The mapping aims to take into account all the interactions and transactions related to the product and understanding of the processes and sub-processes in the chain with a good interpretation of aggregate demand to the successful completion of commands.

For this, performance indicators are associated with different chain processes to allow the company to be evaluated.

\section{Monitoring and Performance Evaluation of Logistics Systems: Method Based on Processes and Multi-agent Approaches}

The quality monitoring is an integral part of any citrus logistics system. It can describe the performance of this system, assess its strengths and weaknesses and identify areas for improvement. 


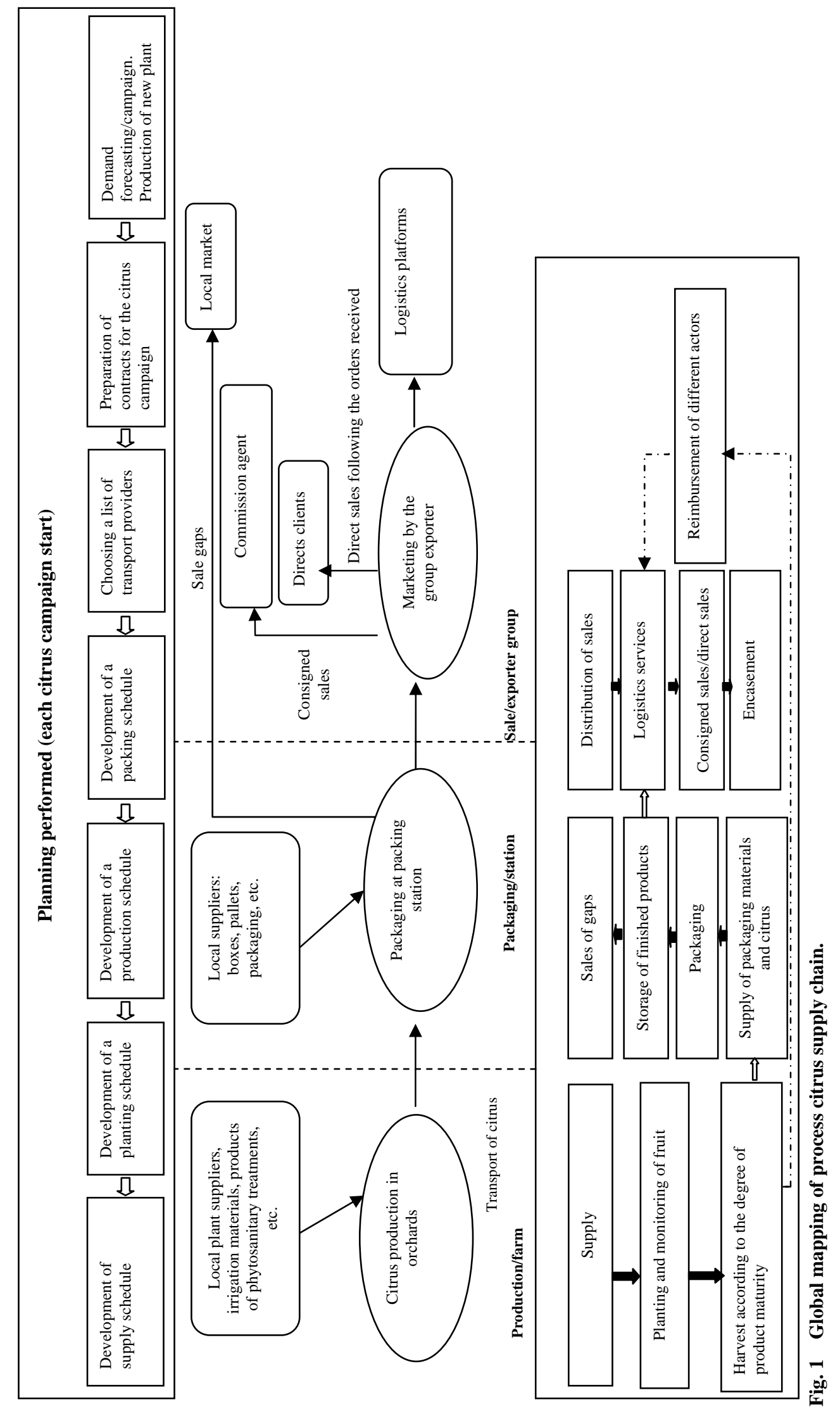




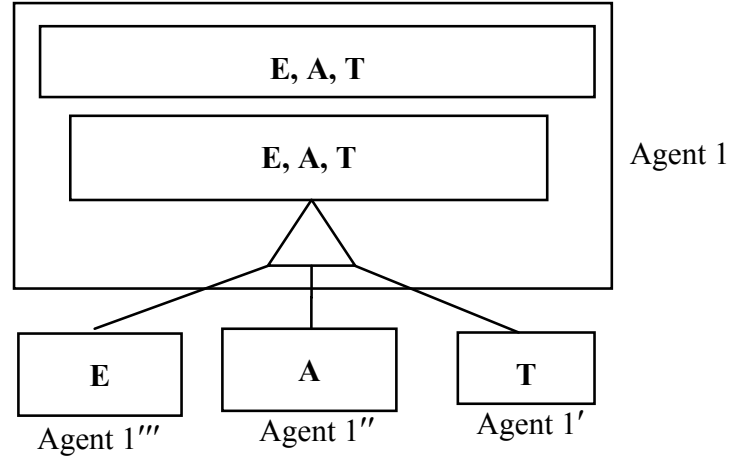

Fig. 2 Agent 1 modeling.

E: local packaging; A: citrus ready for packaging; T: transport (farm-station).

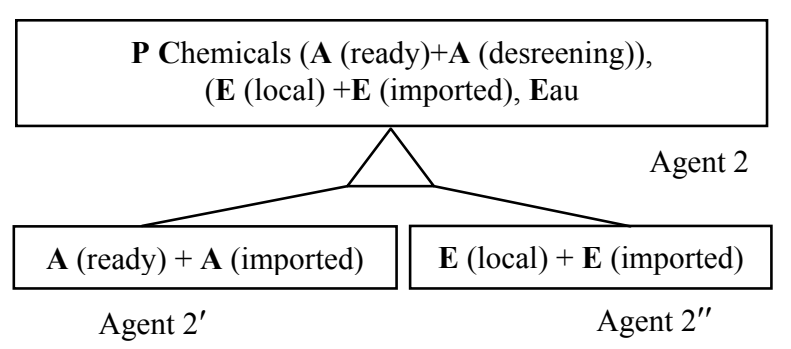

Fig. 3 Agent 2 modeling.

E (local) : local packaging; E (imported) : imported packaging; A (ready) : citrus ready for packaging; A (desreening) : citrus not ready for packaging; P Chemicals : chemicals product; Eau : water.

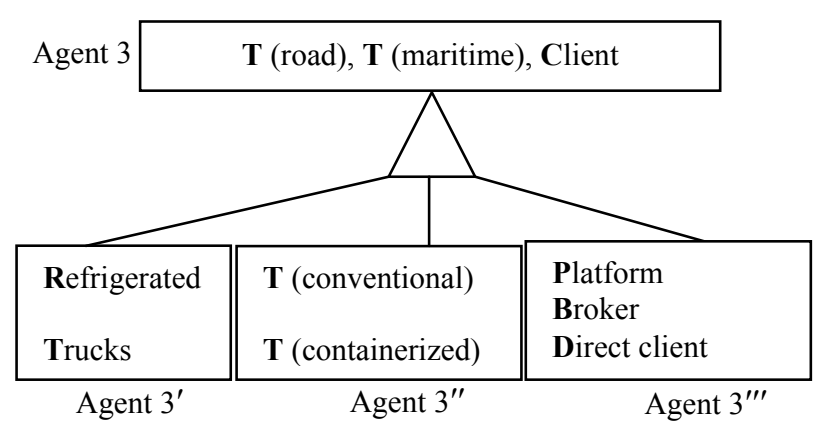

Fig. 4 Agent 3 modeling.

T (conventional): conventional transport; $\mathbf{T}$ (containerized): containerized transport; $\mathbf{T}$ (routier): $\operatorname{road}$ transport; $\mathbf{T}$ (maritime): maritime transport.

To this end, the planning of a supply chain is a complex operation because a string is treated as a point to point connection and a real network as coordination and a global vision. This coordination which is presented in the case of a multi-site company, allows the consideration of client requirements and deadlines imposed by suppliers that remain important to define a reliable planning.

The objective of this section is to assist decision makers to best meet the final client while planning their production and supply.

\subsection{Robust Planning in an Uncertain Environment}

The robust planning has a principal mission:

- anticipate problems that may occur in the various processes of the logistics chain;

- define the best decisions in the context of the reactivity of the supply chain following degrees of freedom of decision maker (the quantity of supply, capacity, and quantity to produce or subcontract);

- integrate uncertain parameters when planning.

\subsection{Modeling of Complex Logistics Chain}

A supply chain is a complex system that must be broken down into subsystems, and each subsystem can represent an entity or functionality set by inputs and outputs with predefined objectives.

There are three types of modeling based on multi-agent approach. The first one is a centralized approach, where a single agent controls the different processes in the chain. The disadvantage of this method is heaviness treatment, deficiency of flexibility and reactivity. The second type of modeling is based on a decentralized architecture where each agent controls and monitors a single process, and exchanges information with other agents. The advantage of this approach is the best local flexibility and reactivity and its disadvantage is evident in the heaviness of overall visibility and the global coordination.

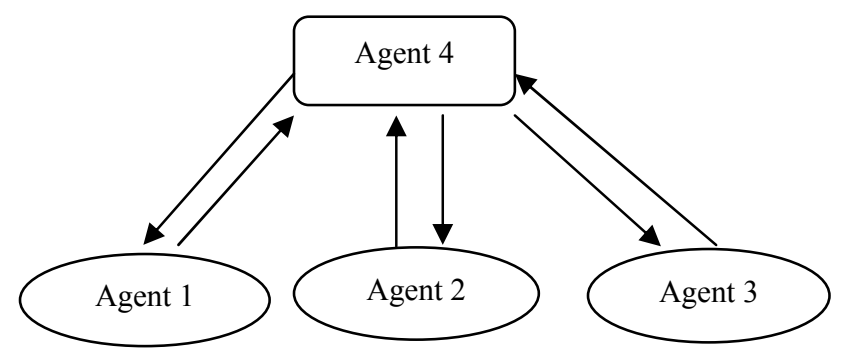

Fig. 5 Agent 4 modeling. 


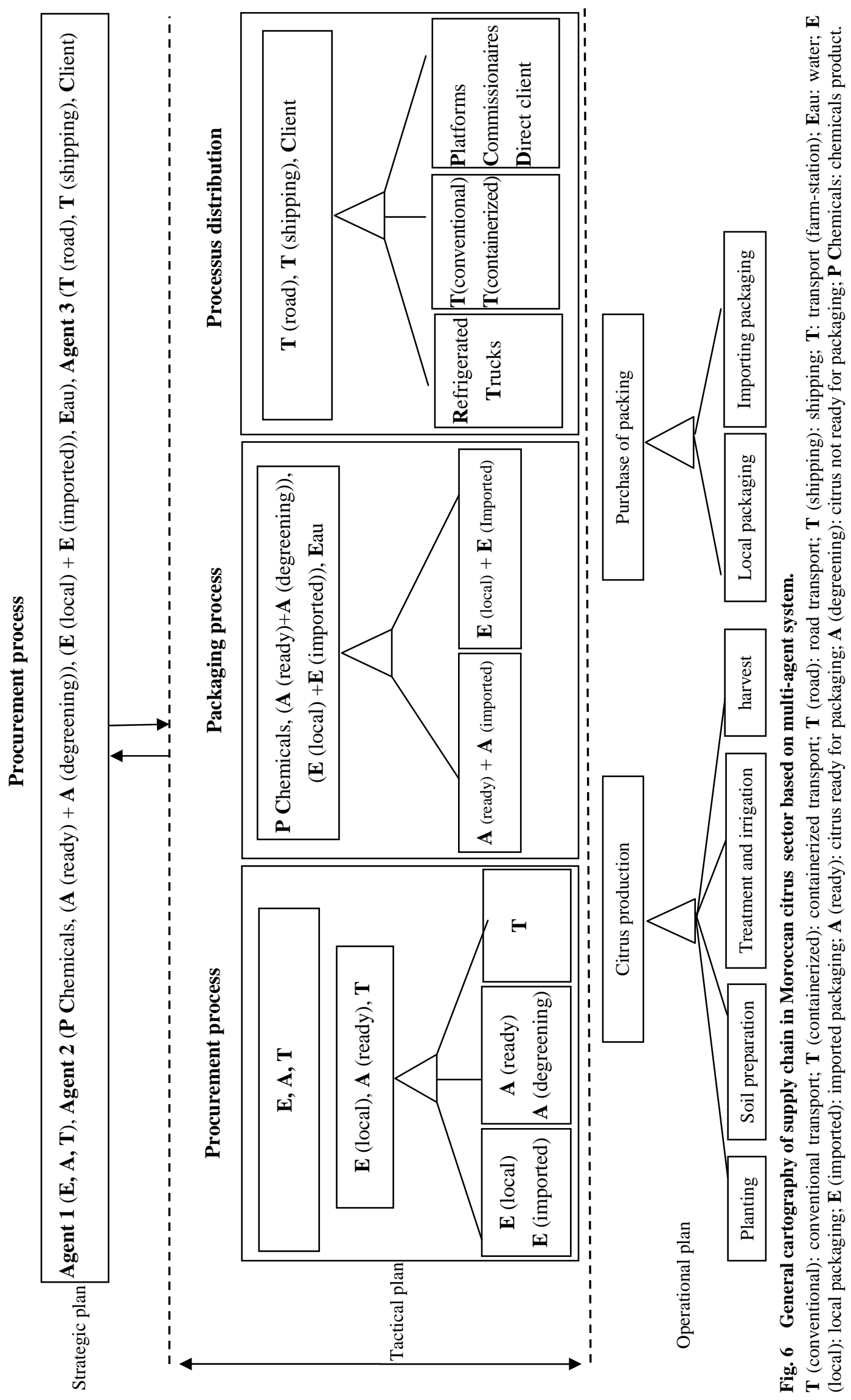




\section{Reactive and Robust Planning of Moroccan Citrus Chain Based on Multi-agent System and Performance Indicators}

A new approach based on the mixing of the decentralized and centralized approach is proposed, where every agent checks a process and passed on a report at the level of the central agent who coordinates with other agents.

The global vision of this architecture is going to insure a reactivity further to changes, review of the objectives in case of unforeseen circumstances and also a better flexibility.

\subsubsection{Centralized Architecture}

Centralized architecture can be modeled by Fig. 7 .

\subsubsection{Decentralized Architecture}

Decentralized architecture can be modeled by Fig. 8 .

\subsubsection{Mixed Architecture}

Based on centralized and decentralized architectures, mixed architecture can be modeled by Fig.9.

\subsection{Restructuring of the Chain Based on a Reactive Approach}

The implementation of performance indicators for the follow-up and the control of the supply chain seem necessary for evaluation of the dynamic state of the chain in particular. We distinguish the global characteristics of the chain which we can define by deadline, cost, quality, as well as the local characteristics for fascinating each party of the chain. Several scenarios are proposed to put the interest of our approach, in particular in a complex economic environment with many variable parameters.

In case we cannot accommodate locally (local agent) to certain scenarios, we call on to the coordinating agent who will make the decision to define new local requirements at the level of every agent to protect the global performance of the chain. It is possible that even in the presence of a restructuring of the chain, the global objectives are partially affected only. We shall develop these scenarios in the following paragraphs.

Fig. 10 shows well that the choice of certain parameters of the chain affects its performance. An optimal choice of these parameters $(Q n, D n, C n)$ stays a sensible compromise. In a real context, the performance of the citrus supply chain is always perturbed by fluctuations (stock and cost) and uncertainties which return indicators at half-mast.

Consequently, the chain is characterized by a new model of functioning ( $Q n f, D n f, C n f)$ where the objective remains to restructure the chain by acting on the local ways or the resources to be able to find the global performance, or the asymptotic performance.

The restructuring is to recalculate the Lagrangian $(L)$ using the following formula:

$$
L=(Q n-Q n f)^{2}+\lambda(D n-D n f)^{2}+\mu(C n-C n f)^{2}+
$$
$£(f(S))$

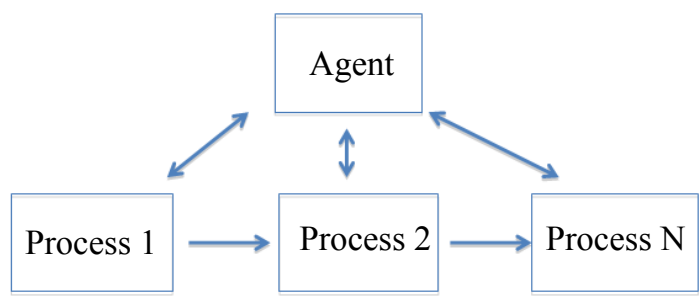

Fig. 7 Centralized architecture modeling.

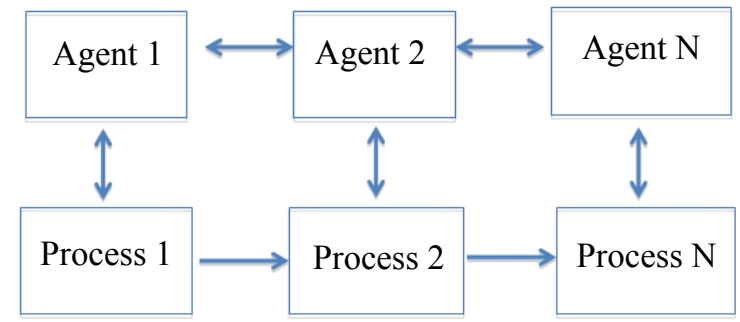

Fig. 8 Decentralized architecture modeling.

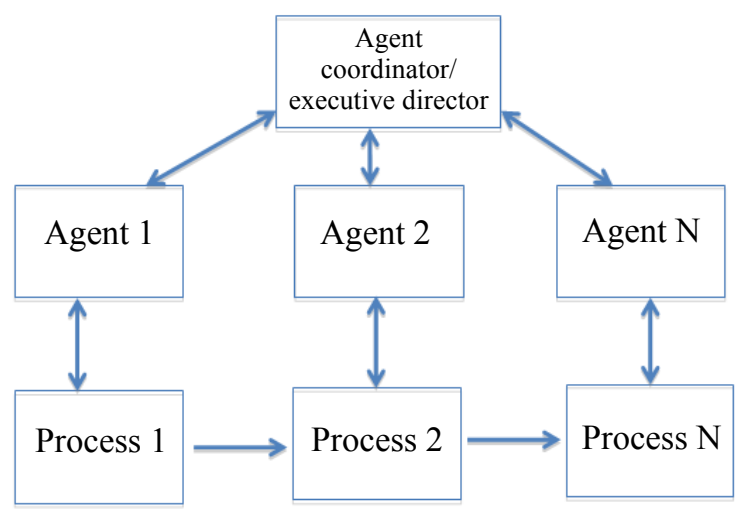

Fig. 9 Mixed architecture modeling. 


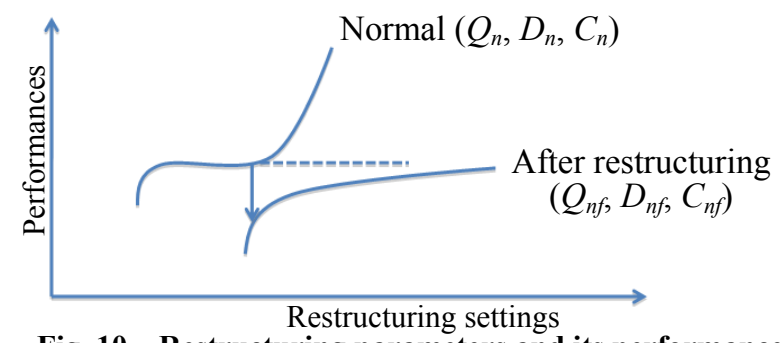

Fig. 10 Restructuring parameters and its performance.

where:

$\lambda, \mu$ and $£$ are multipliers Langrange;

$Q n, D n$ and $C n$ are the initial indicators;

Qnf, Dnf and Cnf are the indicators after restructuring;

$f(S)$ represents the resources to achieve the goals after restructuring.

The minimization of this criterion allows to define the new parameters distributed by the chain and also the objectives which should be protected and those which should be modified.

\subsection{Proposal of a New Model for the Reactivity of the Complex Chain}

As presented, our supply chain consists of a set of interconnected processes, and every process evolves in an uncertain environment which, well obviously, propagates in the other processes and influences the objectives and the performance of the global chain.

Internal variations associated with every process can be compensated with internal actions by requesting the means and the available resources. In case where these uncertainties are very important, the coordination of the chain is going to modify certain internal parameters of the other processes piloted by agents, and to maintain its global performance. Several scenarios can be studied to show the capacity of the chain to protect its global objectives.

The modeling (Fig. 11) which represents the reactivity of a complex chain is proposed:

Indeed, every process possesses a local dashboard piloted by an agent. However, a process is the object of several disturbances which can affect his local dashboard. The role of the local reactivity is to be able to set up corrective actions allowing to mitigate in housing the various uncertainties and the disturbances to protect the local board for a determined horizon.

In case where the internal actions of a process cannot check or accommodate the disturbances which appear at the process, the coordinating agent takes over to redefine the strategy of the chain to protect his global dashboard.

\subsection{Cost, Deadline and Quantity, Key Indicators of the Citrus Supply Chain}

The good management of a citrus supply chain is subordinated, mainly, to the control of its major pillars.

By basing on what precedes, it is noticed that all the processes and agents predefined have major objective to estimate the facts most widely possible to find the most optimal solutions from the point of view of the set levels of the supply chain: better costs, flexibility, better deadline and quantity. Indeed, the best improvements are generally realized when taking into account the possibilities, the problems and the knowledge of each. In continuation of our work, it seems interesting to characterize the performance of our approach in front of disturbances and fluctuations in the environment according to the total cost of production, the best delivery deadline, and the good quantity asked by the customer. For that purpose, in the following, three key indicators of the chain are put: cost, deadline and quantity.

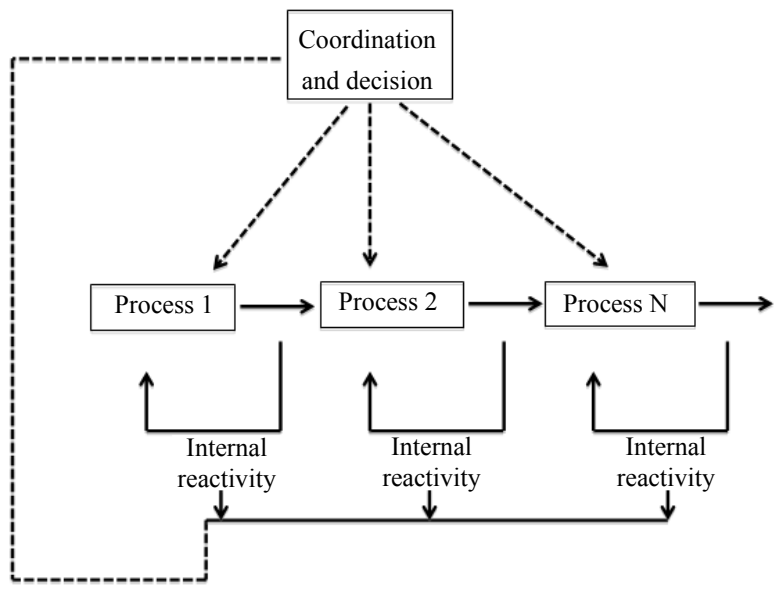

Fig. 11 Modeling of complex and reactive chain. 


\section{Reactive and Robust Planning of Moroccan Citrus Chain Based on Multi-agent System and Performance Indicators}

5.5.1 Indicators of the Citrus Supply Chain: Cost, Deadline and Quantity

\subsubsection{Indicator Based on the Cost}

The major objective of a supply chain is to control the global cost. This cost is calculated according to the partial costs of the various processes and sub process of the chain. For that purpose, there are situations which engender on costs (as the modification of a command, the variation of the raw material, the unavailability of the human resources and the materials, the delays caused by the means of transportation).

The first digital application handled in this article concerns the optimization of the global cost of the studied chain:

$$
\operatorname{Min} C T=\sum_{i \in T} \alpha_{i} C_{i}+\sum_{j \in T} \beta_{j} C_{j} \ldots+\sum_{k \in T} \lambda_{k} C_{k}
$$

where,

$\alpha_{i} C_{i} \leq C_{\max }$, under the constraint of a maximum cost of a process associated with an agent $i$;

$C_{i}$ represents the cost to perform the tasks of a process $i$ controlled by an agent;

$C T$ is the total cost of the process chain;

$T=\left\{t_{1} \ldots t_{k}\right\}$ is the number of agents contributing to the realization of different processes;

$\alpha_{i}, \beta_{j}, \lambda_{k}$ are the weights associated with the contribution of each agent in the tasks.

Often, the cost is an uncertain indicator, disrupted by the fluctuations in the parameters checking the various processes piloted by the various agents of the citrus chain.

The major purpose is to master the global cost of the chain. We fix a cost reference that going to be decomposed into several sub cost references $C_{i}^{\text {ref }}$.

So we can define the gap $e_{i}$ as follow:

$$
e_{i c}=\sum_{i=1}\left(C_{i}-C_{i}^{r e f}\right)^{2}
$$

which represents the gap between reference cost $C_{i}^{\text {ref }}$ and real cost $C_{i}$.

5.5.1.2 Indicator Based on the Deadline and Quantity

We can plan the same approach realized for the cost on two other remaining indicators: deadline and quantity. We define $e_{i Q}$ and $e_{i d}$ the gaps between the references and the real values are as follows:

$$
\begin{gathered}
e_{i d}=\sum_{i=1}\left(D_{i}-D_{i}^{r e f}\right)^{2} \\
e_{i Q}=\sum_{i=1}\left(Q_{i}-Q_{i}^{r e f}\right)^{2}
\end{gathered}
$$

In the practical case, these errors are different from 0 , due to the uncontrollable factors of the chain. We shall define, afterward, bearable thresholds from which it is necessary to plan a strategy of restructuring to obtain an intelligent and autonomous supply chain.

5.5.2 Restructuring of the Supply Chain: Towards a Reactive Chain

The restructuring of a chain consists in seeing again the adopted strategy by making new decisions. This is translated by the implementation of new preventive or still palliative actions. These actions require the modification of certain experimental parameters of the chain to protect its performance indicators.

The gaps which do not exceed certain thresholds $(\varepsilon)$ remain bearable:

$$
\left.\begin{array}{l}
e_{i d}=\sum_{i=1}\left(D_{i}-D_{i}^{r e f}\right)^{2} \leq \varepsilon_{d} \\
e_{i Q}=\sum_{i=1}\left(Q_{i}-Q_{i}^{r e f}\right)^{2} \leq \varepsilon_{Q} \\
e_{i c}=\sum_{i=1}\left(C_{i}-C_{i}^{r e f}\right)^{2} \leq \varepsilon_{c}
\end{array}\right\} \begin{aligned}
& \text { Restructuring is } \\
& \text { necessary }
\end{aligned}
$$

These thresholds are determined from the uncertainties of data (we can exploit the history of the data to define the intervals of variations of the parameters).

If one or many indicators exceeds their tolerance thresholds, the strategies of restructuring following the relevance or the criticality of the indicator are used. Indeed, three categories of restructuring based on the model presented above (Fig. 12) are presented:

(1) Internal restructuring. This restructuring concerns the minor disturbances (small delays, temporary breakdowns, temporary break of stock) which can be compensated/regularized by a modification of the planning which consists in certain 


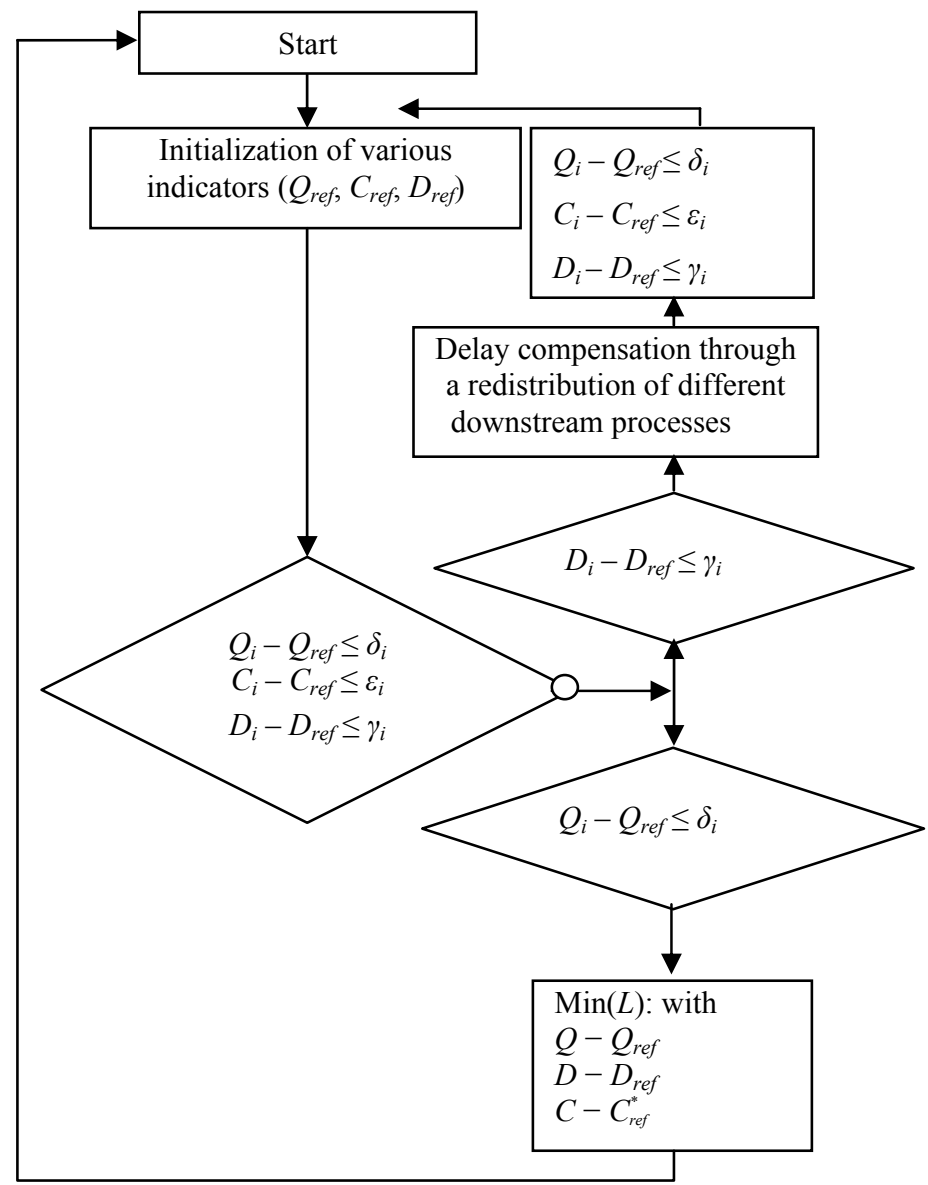

Fig. 12 Algorithm of restructuring based on the architecture of mixed decision.

$\delta_{i}$ : threshold amount set by the decision maker; $\varepsilon_{i}$ : threshold of the actual cost set by the decision maker; $\gamma$ : threshold necessary delay associated with the completion of each process $i$.

cases in adding new ways or in requesting new temporary resources to remedy it without exceeding the tolerance threshold. In this case, the gaps stay under the tolerance thresholds. In case we exceed the tolerance thresholds fixed for every indicator, we shall pass in an external restructuring which will call other agents;

(2) External restructuring. It will be active when the internal restructuring will not allow protecting the local indicators associated to every agent. Indeed, our strategy will consist in requesting the coordinating agent to redefine new local indicators protecting the global objective fixed at the level of the master agent. It supposes that the global objective remains reachable. In the opposite occur, we shall go to the asymptotic external restructuring;

(3) Asymptotic external restructuring. If the global objective is not reachable, even having requested in coalition of other agents of various processes, it is possible to keep certain indicators and to find new references which could be most adapted for others:

$$
e_{T}=C_{T}-C_{T}^{r e f^{*}}
$$

In this case, we intend to modify the global indicator while remaining the closest possible to the initial reference.

\subsubsection{Criterion of Synthesis}

Resting on the Lagrangian criterion, we summarize the various scenarios in the minimization of a quadratic criterion according to three indicators: cost, quantity and deadline:

$$
L=\sum_{i=1}\left(Q_{f}^{i}-Q_{r e f}^{i}\right)^{2}+\lambda \sum_{j=1}\left(D_{f}^{j}-D_{r f f}^{j}\right)^{2}+\mu \sum_{k=1}\left(C_{n}^{k}-C_{r e f}^{k}\right)^{2}+£(f(S))
$$

All the objectives are often difficult to reach. For that purpose, it would be sensible to settle priorities. 
Indeed, the criterion presented previously bases itself mainly on the choice of priority between the cost, deadline and quantity. For example, for a well determined case, we fix the quantity and the deadline as two priority indicators. In this case, the criterion will allow us to obtain a cost under optimization.

For that purpose and to be able to answer the global request of the chain, the criterion $L$ should fix new objectives $\left(Q_{f}, D_{f}, C_{f}\right)$ with two maintained objectives and one modified (* means modified, $Q_{f}, D_{f}, C_{f}^{*}$ ).

We synthesize all the scenarios presented previously by the algorithm of Fig. 12 .

As we have already shown at the global cartography of our citrus supply chain, the processes/agent of the chain are interconnected between them. For that purpose, it is advisable to indicate that a delay can be multiplicative and can propagate at the various processes/agent of the chain. Consequently, it can have a negative impact on the chain studied. To mitigate this problem, applying the methods of estimation of the delay (probability approaches) is suggested. If the delay is generated by a process of departure and as soon as the delay is estimated, two methods on the basis of the model of the architecture centralized/decentralized $\Delta \mathrm{D}_{n}^{i}$ are proposed.

The first method is intended to compensate the overall delay by decomposing into partial delays and distributing them to different processes depending on the flexibility of each. This requires a good understanding of the various processes and the current conditions (resource states).

As for the second method, it is to set up new resources in the various downstream processes in order to compensate the difference detected at each one. This will allow the algorithm to instantly recalculate a new configuration.

In the next section, we will shed some light on adaptive planning which will be closely linked to the restructuring process.

\section{Conclusions}

We position our work in the context of strategic piloting of the citrus supply chain, by focusing on the improvement of its performance. In this context, developed a review of surrounding areas of modeling applied within the framework of management of the supply chain is developed. This brought to hold the hierarchical approaches as a relevant solution. On the first hand, these approaches reflect the reality of the relations of coordination which settle down between the various actors of the same chain. On the other hand, they offer a good compromise between the research for an optimal planning, the synonym for competitiveness, and the decision-making flexibility, the source of reactivity, indeed, in an economic situation characterized by a greater competition.

Indeed, a new modeling of the citrus supply chain is proposed based on the multi-agents approach and indicators of follow-up and benchmarking of its logistic systems to be able to build a new autonomous, strong and reactive chain, and to optimize, to check the flow of subjects and information between its various actors and participants. For that purpose, an approach allowing to identify and to define the assets of a strong and reactive supply chain is proposed with regard to the disturbances and to the uncertainties, resting on a model of mixed piloting (centralized/decentralized). Scenarios are proposed to illustrate this approach.

In the perspectives of our works, we will extend this method to the context of adaptive planning in order to get final intelligent and autonomous chain.

\section{References}

[1] Lizarrage, C. L. V., Dupont L., Gourg D., and Pingaud, H. 2005. "Contributing to Management of Shared Projects in SMEs (Small and Medium Enterprises) Manufacturing Clusters." Presented at 18th International Conference on Production Research (ICPR-18), Salerno, Italy.

[2] Julien, P. A. 1997. SMEs Review and Prospects. 2nd ed.. Paris: Economica. (in French)

[3] Porter, M.1990. The Competitive Advantage of Nations. New York: Free Press. 
[4] Gilmour, P. 1999. "A Strategic Audit Framework to Improve Supply Chain Performance." Journal of Business \& Industrial Marketing 5 (4): 283-90.

[5] Cooper, M., Lambert, D., and Pagh, J. 1997. "Supply Chain Management: More than a New Name for Logistics." International Journal of Logistics Management 8 (1): 1-14.

[6] Supply Chain Council Inc. 2010. SCC Supply Chain Operations Reference Model SCOR Version 10.0. Supply Chain Council Inc.

[7] French Logistics Association. 2006. Repository of the French Association for Logistics. France: ASLOG.

[8] Odette International Limited and AutomotiveIndustry Action Group. Repository EVALOG. France: Odette International Limited and AutomotiveIndustry Action Group.

[9] Valla, A. 2008. "A Methodology for Diagnosing the Performance of a Supply Chain." Dr. thesis, National Institute of Applied Sciences of Lyon. (in French)

[10] Paul, J., and Laville, J. J. 2007. "The SCOR Model of Excellence Vector Supply Chain." Supply Chain Magazine 13: 96-8.

[11] Parunak, H. V. D. 2000. "A Practitioners' Review of Industrial Agent Applications." Autonomous Agents and Multi-Agent Systems 3 (4): 389-407.

[12] Jennings, N. R., Sycara, K., and Wooldridge, M. 1998. "A Roadmap of Agent Research and Development." Autonomous Agents and Multi-agent Systems 1 (1): 7-38.

[13] Labarthe, O. 2006. Modeling and Simulation Oriented Supply Chain Agents in a Mass Customization Context: Models and Methodological Framework. Marseille: Paul Cezanne University. (in French)

[14] Sayouti, A., Aniba, F. O., Medromi, H., and Lakhouili, A. 2007. "Remote Control Based on Multi Agents Systems." Presented at 1st International Conference on RCIS
(Research Challenges in Information Science), Ouarzazate, Morocco.

[15] Ferber, J. 1995. Multi-agent Systems: Towards a Collective Intelligence. France: Jacques Ferber. (in French)

[16] Lambert, M., and Pohlen, L. 2002. "Measure the Global Performance of the Supply Chain." Logistics \& Management 10 (1): 3-20. (in French)

[17] Amrani-Zouggar, A. 2009. "Impact of Supply Contracts on the Performance of Supply Chain: Modeling and Simulation.” Dr. thesis, Bordeaux University. (in French)

[18] Bouquin, H. 2004. Le Contrôle de Gestion (Management Control). 2nd ed.. Paris: University Presses of France. (in French)

[19] Berrah, L. 1997. "Une Approche d'Evaluation de la Performance Industrielle, Modèle d'Indicateur et Techniques Floues Pour un Pilotage Réactif.” Dr. thesis, INP Grenoble School.

[20] Lorino, P. 2001. Performance and Its Indicators. Elements of Definition. Performance Indicators under the Direction of Chantal Bonnefous and Alain Courtois. Paris: Productique-Hermes. (in French)

[21] Epstein, M., and Manzoni, J. F. 1998. "Implementing Corporate Strategy: From Tableaux de Bord to Balanced Scorcards." European Management Journal 16: 199-203.

[22] Chan, F. T. S. 2003. "Performance Measurement in a Supply Chain." The International Journal of Advanced Manufacturing Technology 21 (7): 534-48.

[23] Stalk G., and Hout T. 1990. "How Time-Based Management Measures Performance." Planning Review 26 (9): 26-9.

[24] Biteau, R., Garreau, A., and Gavaud, M. 1991. Dictionary of Industrial Management Terms. France: AFGI (Association of Financial Guaranty Insurers). (in French) 